\title{
Methodology for the Optimal Development of District Heating Systems: Theoretical and Practical Research
}

\author{
Ivan Postnikov ${ }^{1, *}$, Andrey Penkovskii ${ }^{1}$, Ekaterina Mednikova ${ }^{1}$ \\ ${ }^{1}$ Melentiev Energy Systems Institute of SB RAS, 664033, Lermontov st., 130, Irkutsk, Russia
}

\begin{abstract}
The paper presents a synthesis of research results on the development of scientific and methodological support for the comprehensive solution of the main technical, economic and organizational problems of designing, functioning and development of modern district heating systems (DHS). These studies were conducted at the Melentiev Energy Systems Institute of SB RAS (Irkutsk city) by the scientific team of the Laboratory of Heat Supply Systems. Within the framework of the developed scientific and methodological support, the following basic problems were solved: optimization of levels of district heating in DHS with feasibility study for connecting new consumers, selection of optimal forms and models of heating market for DHS, comprehensive analysis and ensuring (optimization) reliability of DHS taking into account the fuel supply of heating sources (HS), and other additional problems. Based on the developed scientific and methodological ensuring following practical researches were carried out on existing DHS schemes of cities of the Irkutsk region: optimal management of DHS in Angarsk, Irkutsk region, taking into account the diverging interests of heating market participants; determination of the optimal scale of development of the existing DHS in Irkutsk based on the optimization of the effective heat supply radius taking into account the reliability of heating to consumers; comprehensive reliability analysis of DHS in Shelekhov of Irkutsk region, taking into account the fuel supply to HS.
\end{abstract}

\section{Introduction}

In Russia, heat supply has great social, economic, energy and ecological importance. Russia produces about $44 \%$ of the world total heat energy produced in district heating systems (DHS). Here the largest potential of energy saving is concentrated (175-190 million tce, more than $20 \%$ of the total consumption of boiler and oven fuel in the country). Realization of this potential necessitates the solution of two interrelated problems.

The first of them consists in transition to the new level of technologies and equipment and assumes complex transformation of the DHS in order to increase their reliability, controllability and profitability. The market of the modern energy efficient equipment and technologies, both domestic, and foreign production that was created and continuing to develop, emergence of the service infrastructure providing servicing of innovative level of power stations promote it.

The second task is formation of methodological bases and principles of creation of new modern DHS, the development of modern information and technological platform and computational tools for management of development and operation of DHS. Implementation of new energy-efficient technologies should be carried out in accordance with the methodology of optimal design of DHS, taking into account their existing condition and modern requirements for efficiency and reliability. The application of the scientific bases corresponding to mod- ern requirements for making decisions on the designing and development of the DHS will allow to organize the process of their innovative transformation, that as much as possible use effects of cogeneration, provides an optimum combination of the district and distributed (decentralized) heat supply to consumers.

The paper presents a synthesis of research results on the development of scientific and methodological support for the comprehensive solution of the main technical, economic and organizational problems of designing, functioning and development of modern DHS. These studies were conducted at the Melentiev Energy Systems Institute of SB RAS (Irkutsk city) by the scientific team of the Laboratory of Heat Supply Systems.

The developed approaches, methods, models and algorithms form an unified methodology, which includes the 3 following main sections:

1) determination of the optimal scale of development of the district heat supply sector in DHS;

2) optimal managing of DHS taking into account different forms of heating market in modern conditions of liberalization of heat power industry;

3) comprehensive analysis and optimization of the reliability of DHS taking into account the full technological stages of production and distribution of heat energy.

The following is a thesis description of the main points of these methodological developments and the results of practical research (case studies) carried out using the developed methodological ensuring.

\footnotetext{
* Corresponding author: postnikov@isem.irk.ru
} 


\section{Methodology}

\subsection{Determination of the optimal scale of devel- opment of the district heating sector in DHS}

The technique for territory zoning by type of heat supply was developed, which consists in dividing the urban area into zones of district and distributed (decentralized) heating based on the determination of the heat load density (HLD). A mathematical model is proposed for optimizing the levels of centralization of heat supply based on the criterion of linear heat density (LHD). The analysis of the impact of standard LHD values on the optimal levels of centralization of heating and the analysis of separated of technical and economic factors on results of heat and power planning are provided.

Mathematical models and methods have been developed for solving the following problems of determining the optimal scale of new and developing DHS: 1) determination of the optimal coverage areas of existing heat sources (HS) and the rational extent of their pipelines of heat network $(\mathrm{HN})$ based on an indicator of the effective heat supply radius (EHSR); 2) assessment of the appropriateness of enlargement/downsizing of the system; 3) the allocation of consumer zones requiring the construction of new HS; 4) preliminary selection of new HS locations.

To coordinate the proposed methods and models, a combined algorithm has been developed that combines various types of computing process (linear, branched, cyclic, etc.) and allows you to take into account the changing parameters when solving a mathematical model. In the framework this algorithm a method was proposed for substantiating decisions on connecting consumers to DHS based on the connection efficiency coefficient (CEC) of a new consumer.

These methodological developments presented in detail in publications [1-5].

\subsection{Optimal managing of DHS taking into ac- count different forms of heating market in mod- ern conditions of liberalization of heat power industry}

Organizational, structural and mathematical models have been developed to find the optimal distribution of heat load between district HS taking into account the interests of different market participants in the DHS. For each model appropriate algorithms were developed for the realization of calculations. The obtained results allow us to analyze the impact of various conditions of the model on the main technical and economic indices of DHS (optimal distribution of heat load between sources, optimal flow distribution in the $\mathrm{HN}$, volumes of heat energy consumption and costs for its production and transportation, heat energy prices, etc.). Based on this analysis, decisions on justify the method of tariff regulation for consumers in DHS of any complexity and scale are made. Special attention is paid to the consideration of the actual organizational model "Unified Heat Supply Or- ganization" (UHSO), for which balanced solutions was obtained for each participants of the heating market, which ensure the needed consumer demand.

A comprehensive scientific and methodological ensuring has been obtained for solving the problems of functioning and developing DHS in market conditions, based on a combination of methods and models of the theory of hydraulic circuits (THC), the theory of industry markets, approaches to game theory and engineering fundamentals for the design of pipeline systems. As a result of optimization of the heating market, based on the methodology of redundant design schemes of DHS, optimal levels of production and consumption of heat energy are determined that correspond to market equilibrium (equal supply and demand for heat energy), taking into account benefits of each participants of the heating market in DHS.

These methodological developments presented in detail in publications [6-11].

\subsection{Comprehensive analysis and optimization of the reliability of DHS taking into account the full technological stages of production and distribu- tion of heat energy}

A methodology has been developed for a comprehensive analysis of DHS reliability taking into account fuel supply to HS, which contains a number of scientific and methodological approaches, methods and models aimed at evaluating reliability taking into account technological connectivity, continuity and mutual influence of internal and external factors of fuel supply processes, production and distribution of heat energy. Developed comprehensive approach provides the maximum level of systematic solution to considered problems of analysis and synthesis of the reliability on each stages of the entire considered technological chain of heat supplying. The algorithm for the comprehensive analysis of the reliability of the DHS taking into account the fuel supply to HS includes the following main steps: 1) imitating modeling of the functioning of the system of fuel supply (SFS) based on the statistical test method (Monte Carlo method); 2) probabilistic modeling of the functioning of DHS based on the apparatus of markov random processes; 3 ) modeling of post-failure thermo-hydraulic modes in $\mathrm{HN}$ based on models of THC; 4) calculation of nodal reliability indices (RI) combining the results of assessing the probabilities of DHS states and levels of heat supply to consumers in these states. As a result, the maximum emergence effect for the considered processes of generation and distribution of thermal energy in the DHS is achieved, which, in combination with the nodal reliability indices provides the DHS reliability evaluation best corresponding to real conditions.

Special methodological approaches to the modeling of non-ordinarity and dependent events in the DHS are proposed, which are considered at the level of probabilistic modeling of functioning of the DHS when solving problems of analysis and synthesis of DHS reliability. A case studies based on calculated experiments for DHS schemes showed the area of required use of modified 
markov random models taking into account nonordinarity and dependent events in the DHS.

A technique has been developed to ensure (or increase) the parametric and operational reliability of the DHS, consisting of a number of mathematical models and approaches that can determine such reliability parameters of system components (failure and restoration rates) that provide the required level of reliability of heat supply to consumers at the minimum cost of achieving these parameters and constrains on its technically possible values. In the framework of this technique the formalization of the functions of prosumers with additional heat power and time redundancy due to its own HS was proposed. To account for the functioning of prosumers the corresponding formalized components are integrated in the model for calculating of nodal RI for taking accounting an additional functional and time redundancy.

These methodological developments presented in detail in publications [12-16].

\section{Case studies}

\subsection{Determination of the optimal scale of devel- opment of the existing DHS of Irkutsk city based on the optimization of EHSR taking into account the reliability}

The developed methodological support for determining the optimal level of district heating was applied for the DHS of Irkutsk city. The general scheme of this system is shown in Fig. 1. The total length of the HN from the district HS (Novo-Irkutskaya Combined Heat \& Power Plant or NICHPP) is $474.3 \mathrm{~km}$, including $112.9 \mathrm{~km}$ of transmission pipelines (TP).

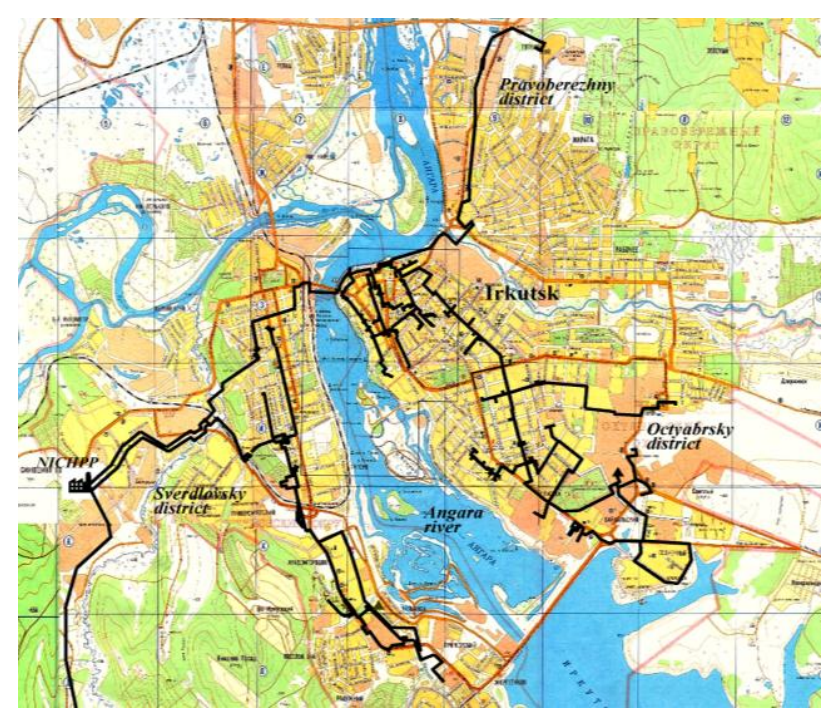

Fig. 1. General scheme of the DHS of Irkutsk on the city map

A calculated scheme of the considered DHS with decisions on EHSR is presented in the Fig. 2. Its values for the NICHPP disregarding reliability requirements along the TP and their branches are limited by nodes highlighted in red in the Fig. 2. The values of the radius vary from
$2 \mathrm{~km}$ (the least distance between the consumer and source) to $15.5 \mathrm{~km}$. An reliability analysis of DHS shows that the standard values of nodal RI are not met for some nodes that belong to the zones of EHSR. According to the reliability indices obtained, we adjusted EHSR in the considered system. In the Fig. 2, the boundaries of EHSR, considering reliability, are shown in blue color and dashed lines. Thus, the maximum EHSR for the NICHPP, considering the reliability requirements, will decline from $15.5 \mathrm{~km}$ to $14.6 \mathrm{~km}$ and the total length of TP in the zone of EHSR will shrink by $4.2 \mathrm{~km}$ and make up $67.7 \mathrm{~km}$. According to the obtained results, considering reliability requirements, the zone of EHSR embraces $284.3 \mathrm{~km}$ of network out of $474.3 \mathrm{~km}$, i.e. $40 \%$ of the networks are beyond EHSR zone. Specific heat cost for the longest branches of TP and average specific heat cost for the system are presented in the Fig. 3. Correlation between the heat load and a material characteristic of the heat network has a significant influence on the specific heat cost for each node. The greater the specific material characteristic of the heat network (per heat load unit), the higher the specific heat cost and vice versa [1-3]. All network sections have different specific material characteristic and EHSR depends on it.

In addition to the proposed method for determining the optimal EHSR, a method has been developed for assessing the effectiveness of connecting a new consumer, which consists in determining the maximum length of $\mathrm{HN}$ pipeline from the point of connection of new consumer to the existing DHS. Fig. 4 presents the maximum length of the pipeline from the point of connection to the existing $\mathrm{HN}$ to new consumers depending on their heat load and different temperature modes of $\mathrm{HN}$.

So, for example, from Fig. 4, it can be determined that connecting a new consumer is effective if the pipeline is constructed at the basis of $500 \mathrm{~m}$ per $12.5 \mathrm{GJ} / \mathrm{h}$ at a supply/return temperature of $138 / 70^{\circ} \mathrm{C}$ (or at a temperature difference in supply and return pipelines equal to $68^{\circ} \mathrm{C}$ ). A lower temperature difference in supply and return pipelines in the network section is characterized by an uplift in capital and operating costs. Therefore, the maximum length of the heat pipeline declines.

Connection of new consumers within the zones of EHSR, taking into account the requirements for reliability, will decrease the growth of operating costs in DHS, reduce heat losses and provide the required level of system reliability.

Heat supply to consumers outside the EHSR zone, as a rule, requires the construction of a new HS. At the same time, the expansion zone of EHSR (that is, connecting new consumers) cannot be determined by only one it level due to the irregular distribution of heat loads on the system. To solve this problem, it is proposed to use an additional criterion of the local EHSR, which allows one to assess the economically feasible distance between the consumer and the point of connection to the district network.

The obtained values are recommended to be updated annually or when EHSR changes due to a considerable change in the connected heat load of consumers and total length of $\mathrm{HN}$ pipelines. 


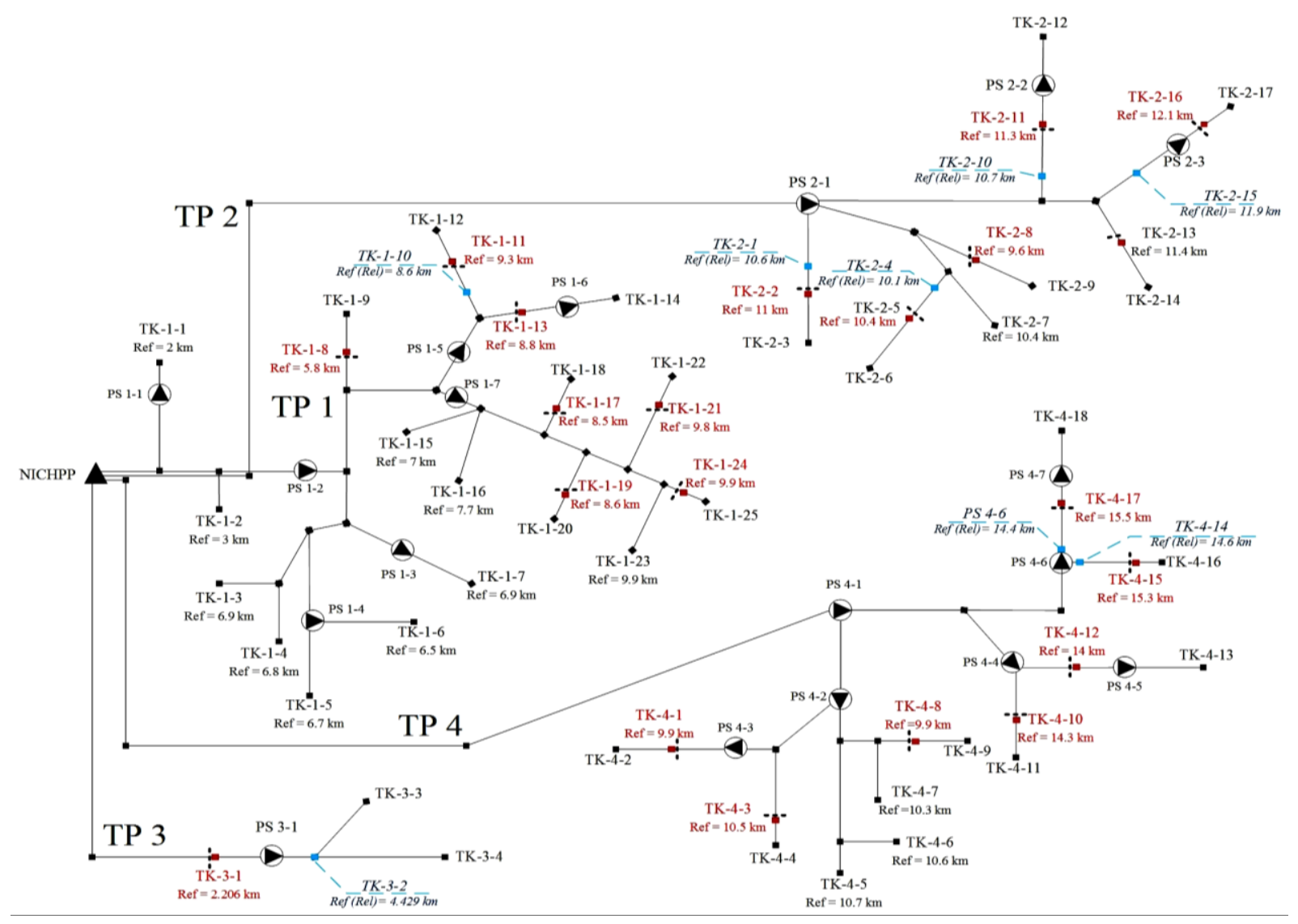

Fig. 2. Calculated scheme of the DHS of Irkutsk with decisions on EHSR: red nodes are corresponded decision without accounting the reliability; blue nodes are corresponded decision with accounting the reliability (TP1-TP4 - transmission pipelines)

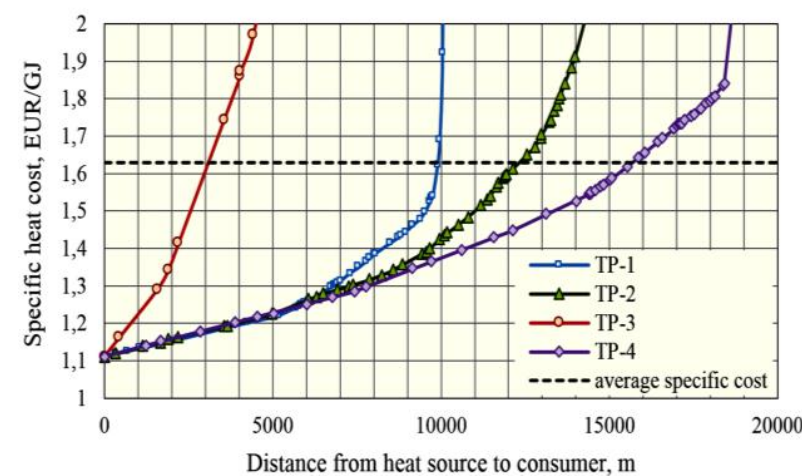

Fig. 3. Specific heat cost for the longest branches of TP of the DHS in Irkutsk city on based NICHPP

\subsection{Optimal management of DHS in Angarsk city (Irkutsk region) taking into account the diverg- ing interests of heating market participants}

Practical research has been carried out based on scheme of the existing DHS in Angarsk city using the developed methodological support for optimal managing DHS in the conditions of the market organization of relations between the subjects of the city's heat supply.

A general scheme of the studied system on the plan of Angarsk city is presented Fig. 5. A calculated model of this system is shown in the Fig. 6, which is obtained by aggregating the initial scheme.

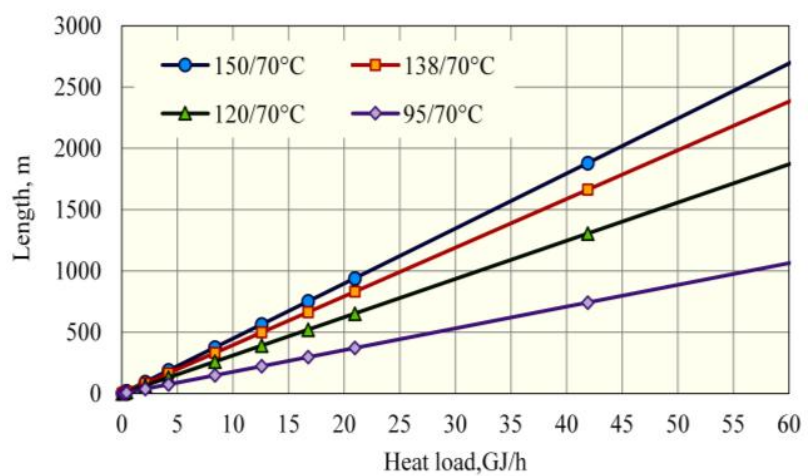

Fig. 4. Maximum length of the pipeline from the point of connection to the existing DHS in Irkutsk to the new consumer

The heat loads of the Angarsk is covered by three district HS: CHP-1, CHP-9, and CHP-10 of the energy company "Irkutskenergo". The total heat power of these sources is $4177.8 \mathrm{Gcal} / \mathrm{h}$. The calculated scheme of the DHS of Angarsk consists of 1273 network sections and 1242 nodes, of which 534 are aggregated (jointed) consumers.

The following initial data is used in the practical research: heat loads of consumers, functions of demand for heat energy, cost functions for $\mathrm{HS}$, parameters of $\mathrm{HN}$ sections (lengths, diameters, etc.), annual schedule of heat loads (schedule and Rossander equation), climatic parameters (mainly, outside air temperatures); cost indices (electricity tariff, fuel price, etc.), and other data. 


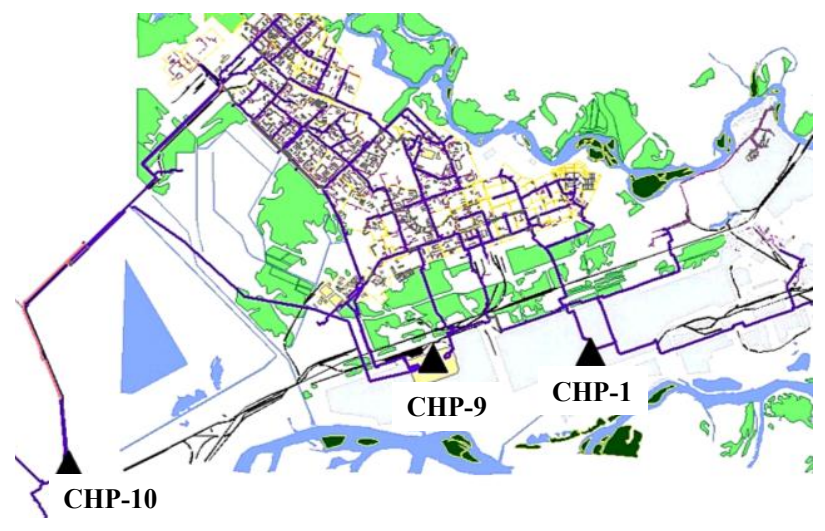

Fig. 5. Scheme of the DHS in Angarsk on the city map

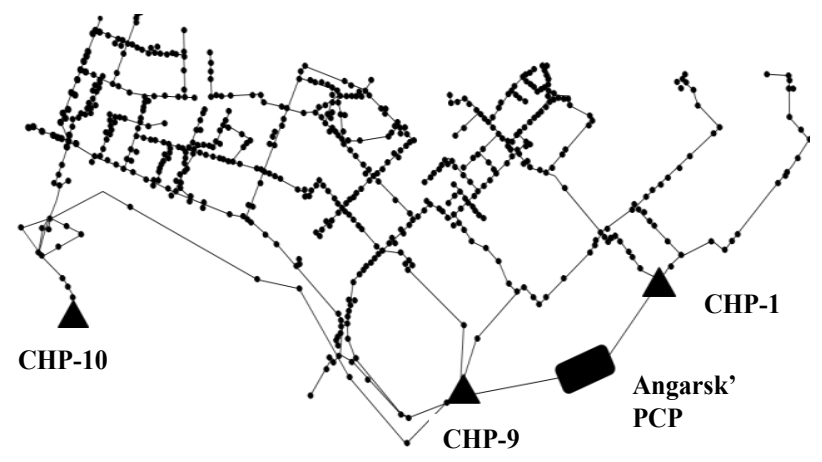

Fig. 6. Calculated scheme of the DHS in Angarsk

The studies of the heat energy market in Angarsk were carried out in order to determine the impact of the form of organizing heating to consumers on the technical and economic indices, including the optimal distribution of heat load between HSs, costs for the production and distribution of heat energy, as well as prices for heat energy for different categories of consumers.

The calculation for considered DHS was carried out for several possible options for organizing heat supply to consumers in Angarsk, including the "Single Buyer" model with a competitive market and a number of models in the form of UHSO with various methods of tariff regulation, including those with free pricing. As a result of calculations, optimal solutions were obtained for the following indicators: HS capacity taking into account their effective participation in covering heat loads, dis- tribution of covering zones for each HS, flow distribution in the HN, costs of operation and development of the system, prices for thermal energy.

The results for the UHSO model with free pricing (liberalized monopoly market) are shown in Fig. 7. For the considered model, CHP-9 covers $57.5 \%$ of the total heat load of consumers, the share of CHP-10 is $27.7 \%$, and CHP-1 is $14.8 \%$. At the same time, the average annual equilibrium tariff for household consumers and will be $733.2 \mathrm{rub} / \mathrm{Gcal}$, and for the largest industrial consumer Angarsk petrochemical plant (Angarsk PCP) will be $965.1 \mathrm{rub} / \mathrm{Gcal}$. The total revenue of the UHSO from the sale of heat energy to consumers will amount to 5.63 billion rub; and its profit for under calculated period will be about 1 billion rub or $17.7 \%$.

The results for the model "Single buyer" in the HN (competitive heat market) are shown in Fig. 8. The calculation for this model showed that $28.5 \%$ of the heat energy in the system is generated on CHP-1, 44\% - on CHP-9 and 27.5\% - on CHP-10. The main share of the generated heat energy (76\%) falls on household consumers, for which the price of heat energy will be 695.2 $\mathrm{rub} / \mathrm{Gcal}$, and for Angarsk PCP the price of heat energy will be set at $859.3 \mathrm{rub} / \mathrm{Gcal}$.

The results obtained make it possible to choose the most effective forms of organizing heat supply (heat energy market), depending on the conditions under consideration DHS. A diagram with a comparative analysis of the main indices of the calculations for various forms of the heat energy market for the DHS in Angarsk is presented in Fig. 9. As seen from this diagram, studies of the DHS showed that the form of organization of heat supply to consumers significantly affects not only the total heat production for HSs and its distribution between them, but also on other technical and economic indices of the system. A comparative analysis of the considered models for optimizing heat supply in Angarsk (heat energy market) revealed that its optimal form of organization is UHSO model when regulating the heat energy tariff for household consumers at the level of average total costs. At the same time, the maximum equilibrium consideration of the interests of each market participant in the system is ensured and optimal technical and economical indices of the system are achieved.
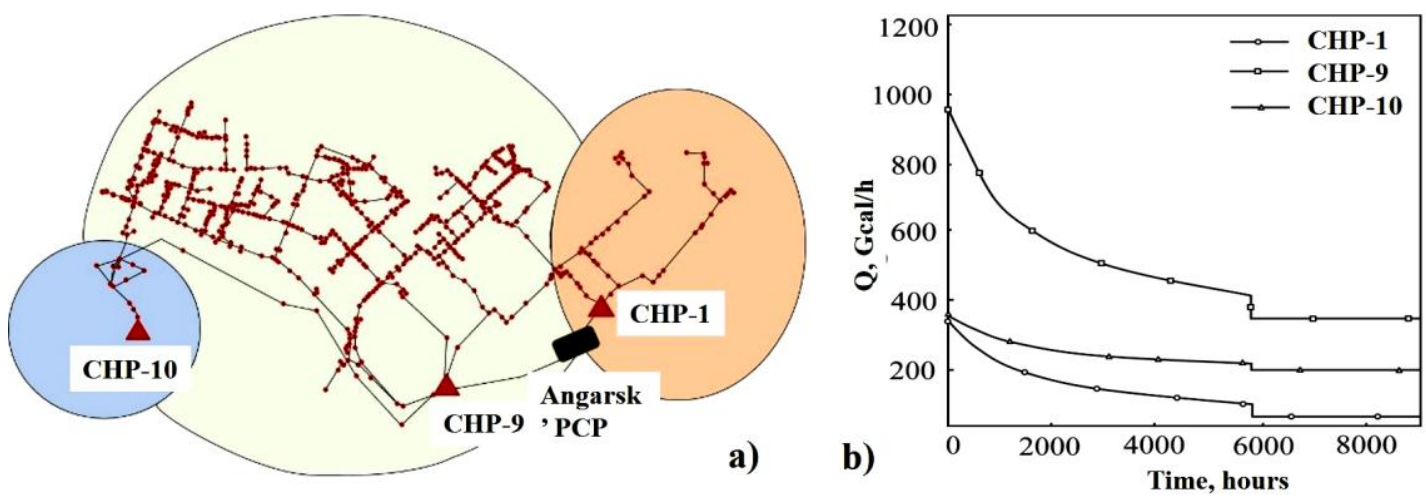

Fig. 7. Distribution of coverage areas (a) and load schedules (b) of district HS in the DHS of Angarsk in the conditions of "Unified heat supply organization" model with free pricing (monopoly market) 

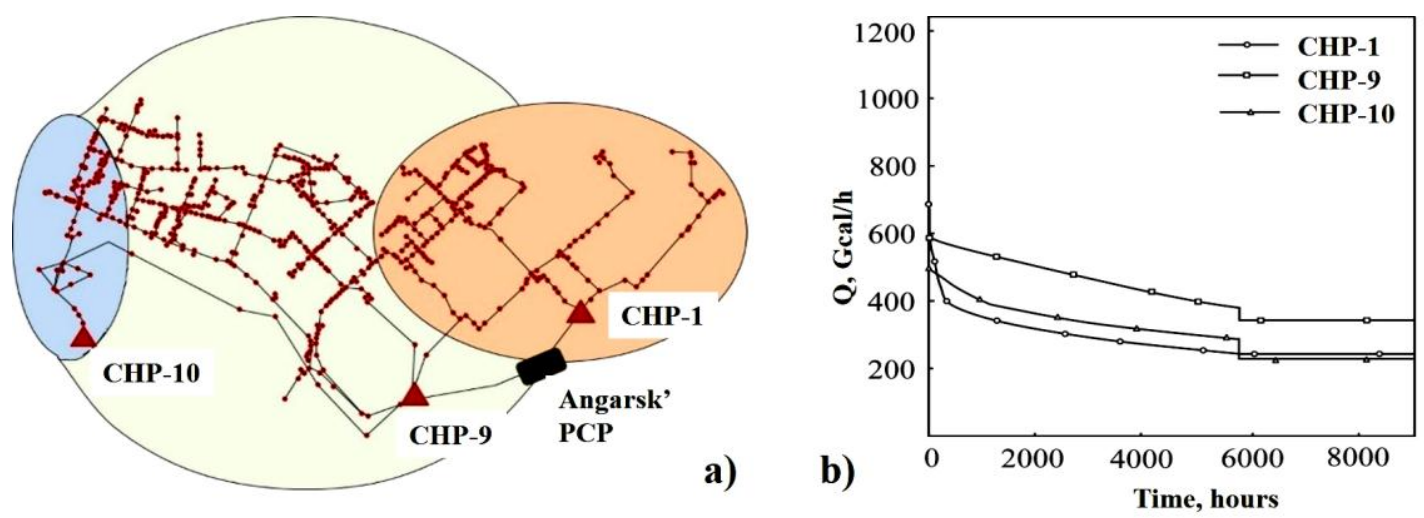

Fig. 8. Distribution of coverage areas (a) and load schedules (b) of district HS in the DHS of Angarsk in the conditions of "Single buyer" model in HN (competition market)

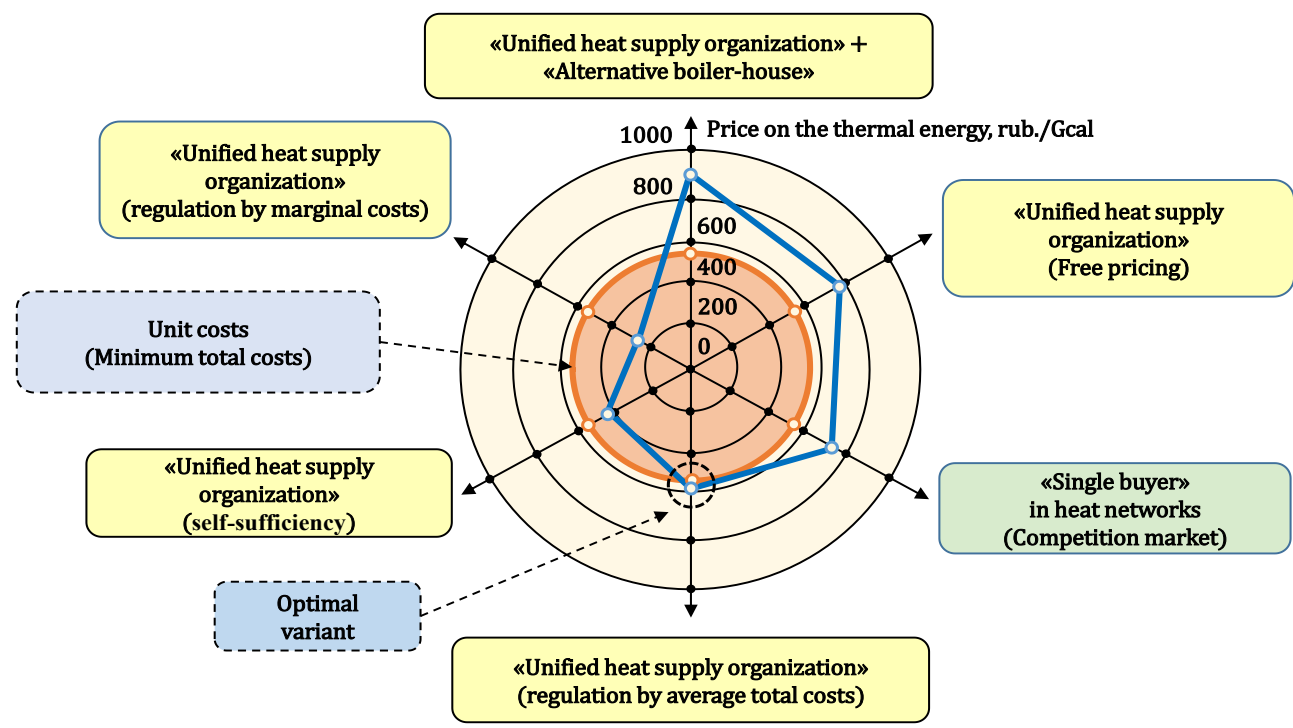

Fig. 9. Results of the comparative analysis of the various forms of the heat energy market for the DHS in Angarsk

\subsection{Comprehensive analysis of the reliability of the DHS in Shelekhov (Irkutsk Region) taking into account the fuel supply to HS}

The developed methodology for a comprehensive analysis of the reliability of DHS was applied on the scheme of the existing DHS in Shelekhov city (Irkutsk region) with district HS (CHP-5 of the energy company "Irkutskenergo") with a capacity of $1843 \mathrm{GJ} / \mathrm{h}$ (440 Gcal/h with peak boiler) and district $\mathrm{HN}$ with a total length of transmission part of $15.7 \mathrm{~km}$.

The calculation schemes of the considered DHS are presented in Fig. 10: the initial general scheme on the city map (a) and the calculated scheme (b) obtained by aggregating the system components (network sections and nodes-consumers). According to an comprehensive approach to the analysis of the DHS reliability, the DHS calculated scheme for reliability modeling is formed by combining the $\mathrm{HS}$ and $\mathrm{HN}$ calculation component schemes [12-15]. The final aggregated calculated scheme of the DHS obtained in this way consists of 89 components, of which 41 components correspond to sections of $\mathrm{HN}$ and 48 components correspond to main technological units of HS.
On the basis of the obtained calculated scheme, the graph of DHS states is formed, shown in Fig. 11. The structure of the states and events is formed with the condition of the Poisson stream of events (simplest stream). The element number of the graph corresponds to the number of the failed component of the studied system.

States on the graph are grouped according to combinations: to the left of the fully operational state " 0 " there is a subset of failure states of HN components (from 1 to 41 ), to the right is a subset of failure states of HS components (from 42 to 89), their combinations are given below as complex states of simultaneous failures of $\mathrm{HN}$ and HS components which are indicated by their numbers with a "+" sign. The event structure also takes into account the interruptions of fuel supply to HS or the functioning of SFS. To take into account possible fuel shortages at HS (STS failures), two additional states with numbers 90 and 91 (Fig. 11) have been added to the general structure of the DHS states, corresponding to the range of fuel shortages ( $\min$ and max). According to the previously described methodology for a comprehensive analysis of the reliability of DHS, these fuel shortages are determined based on the results of simulation modeling of fuel supply to HS, carried out using the method of 


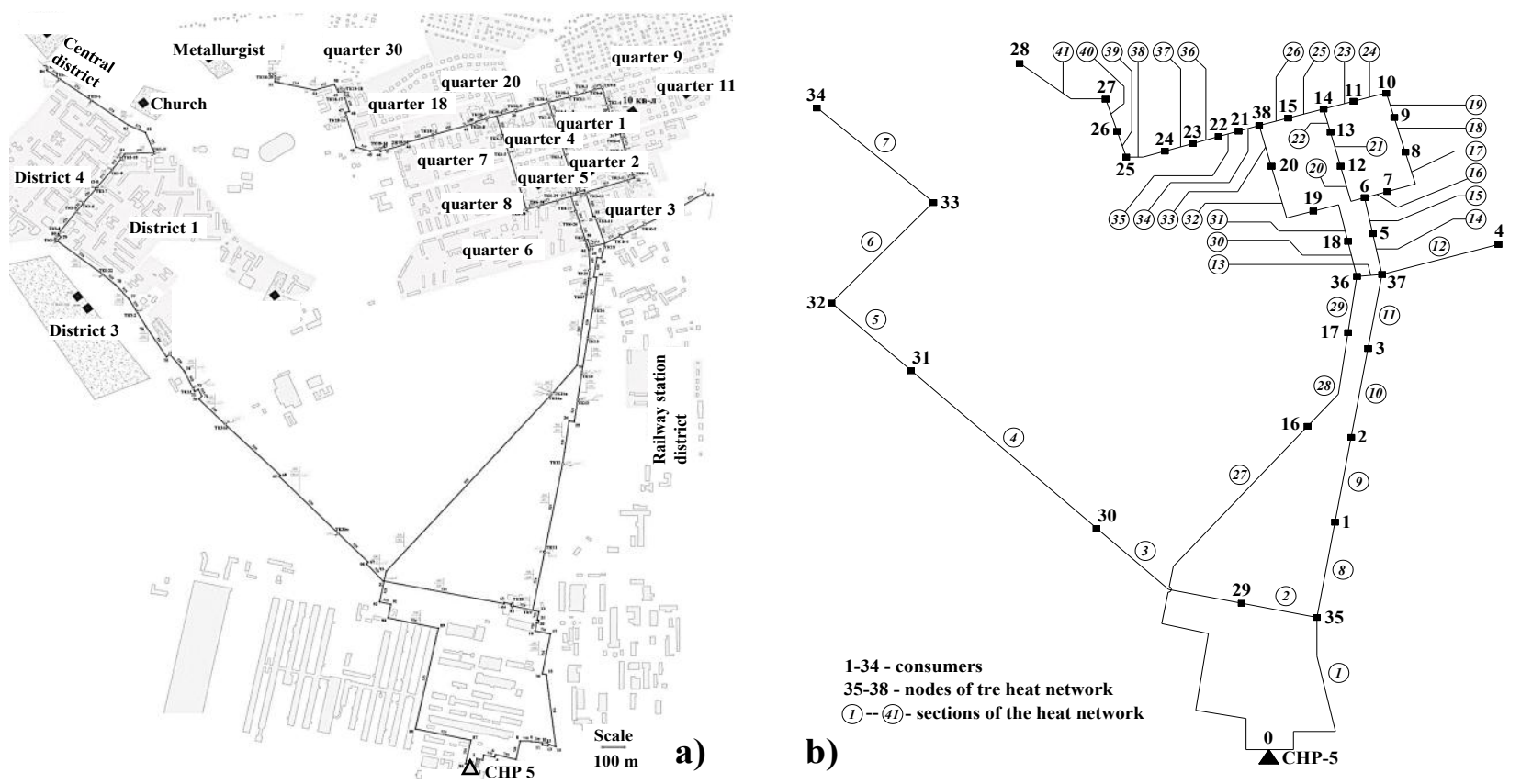

Fig. 10. Schemes of DHS in Shelekhov: a) general scheme on the city map; b) aggregated calculated scheme with unified consumers

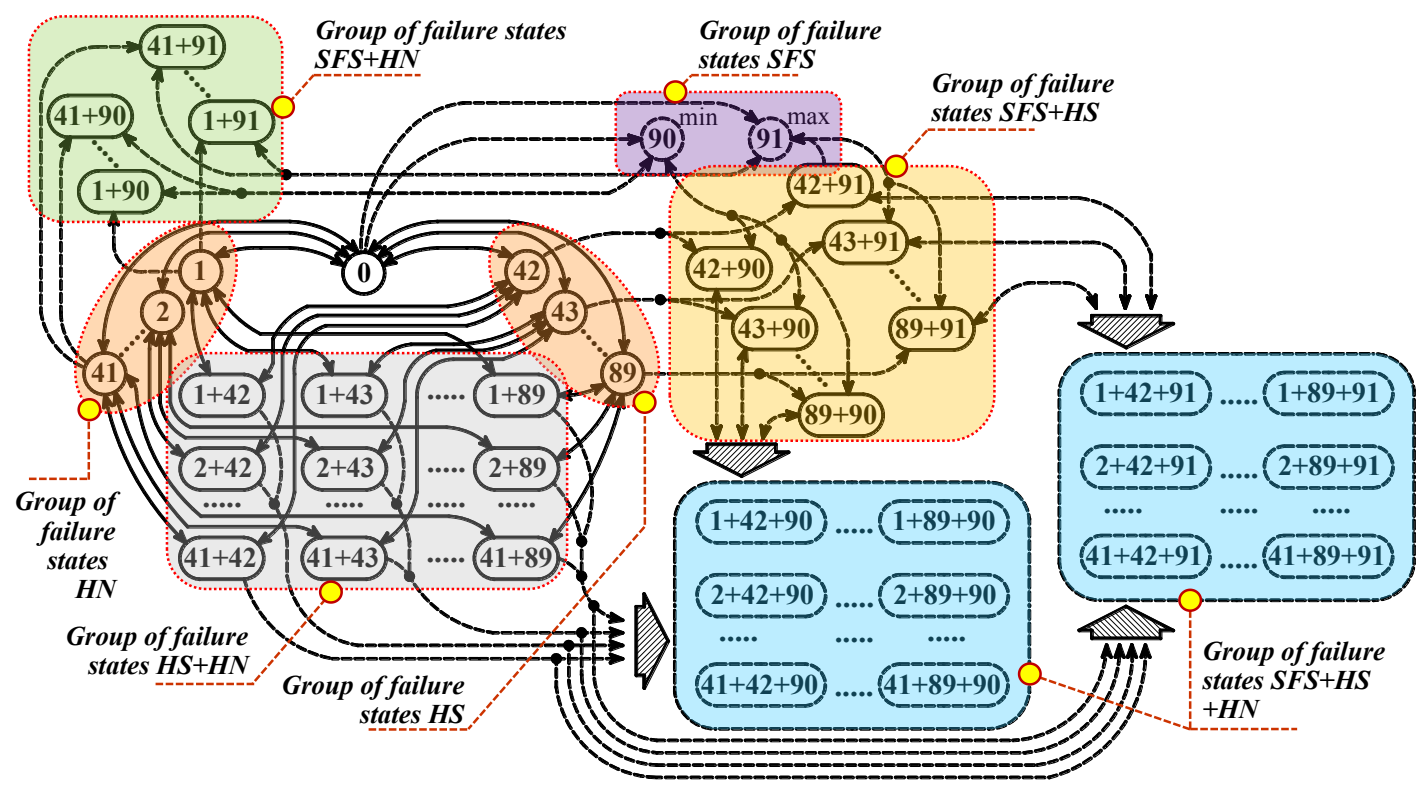

Fig. 11. Graph of the states of DHS in Shelekhov tacking into account the functioning of SFS (i.e. states corresponding to shortages of fuel supply to HS - 90 and 91)

statistical tests (Monte Carlo method) based on actual data on the supply and demand of fuel. These states of possible fuel shortages are combined with $\mathrm{HS}$ and $\mathrm{HN}$ failures and expand the graph with new groups of corresponding states (Fig. 11).

Probabilistic modeling of the functioning of DHS in Shelekhov to assess its reliability was carried out using the markov stationary model in accordance with the structure of states and events described by the presented graph (Fig. 11). This process is described by the corresponding system of linear stationary Kolmogorov equations containing more than 3000 variables. The result of its solution is probabilities of all considered states, which are then used together with the results of calculations of post-emergency modes to determine the nodal RI.

Determination of the levels of heat supply to consumers in different states of DHS (post-emergency modes of DHS), including taking into account interruptions of the fuel supply to HS, it is carried out on the basis of multivariate calculations of the flow distribution in the network using methods of THC. The results of these calculation for identification of post-emergency modes in DHS contain a significant amount of data. The relation of the levels of heat supply to consumers in different states corresponding to failures of $\mathrm{HS}$ and $\mathrm{HN}$ components is presented in Fig. 12. 


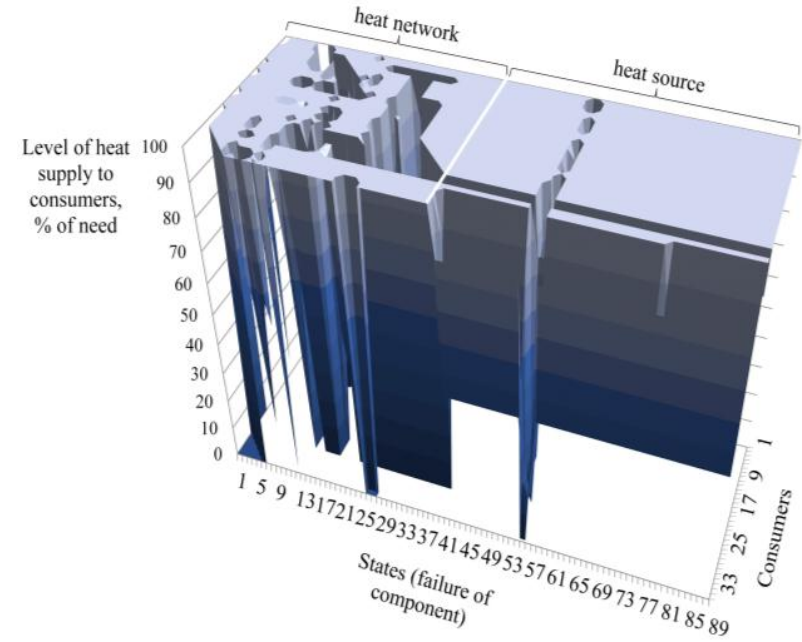

Fig. 12. Levels of heat supply to consumers in case of failures of components of DHS subsystems (HS and HN)

The results of the comprehensive and decomposition analysis of the reliability of DHS in Shelekhov are presented in summarized form in Fig. 13 and Fig. 14, where the ranges of values of the availability factor (AF) and the failure-free operation probability (FOP) are given as for a comprehensive solution and for the subsystems under consideration separately. Based on the decomposition of nodal RI (AF and FOP), the degree of impact of each of subsystem on the total level of reliability of heat supply to consumers is determined. Within the limits of the RI ranges presented in the diagrams, their values are contained for all considered consumers of the system. Comparison of the obtained indices with the standard values showed that the requirements for AF are not ensure for all consumers of the system, for FOP - for 32\% of consumers. Changes in nodal RI for considered subsystems of DHS in relation to the integrated assessment level are shown in Fig. 15.

Analysis of the presented results allows us to formulate the following conclusions about preliminary general directions for improving the reliability of heat supply to consumers of DHS in Shelekhov.

1. Fuel supply interruptions on HS in the considered system reduce the reliability of designed level of heat supply to consumers to a greater extent than failures of HS and HN components. This is confirmed by lower values of AF for SFS compared with DHS (Fig. 13 and Fig. 15). The range of increase in its values to the standard level is from 1 to $9.3 \%$. Improving the reliability of SFS is achieved by regulating and increasing fuel reserves, providing the system with additional sources of fuel and a more reliable system for its transportation.

2. Index AF, calculated relative to HS, has the highest values, and for some consumers it complies with the standard. For the group of jointed consumers with the highest values of this index, achieving its standard level will require a minimal redundancy in the HS scheme. For other consumers, HS-related AF is low. To increase it, more significant measures for increasing of functional and structural HS redundancy will be required. It is also necessary to take into account that the installed heat

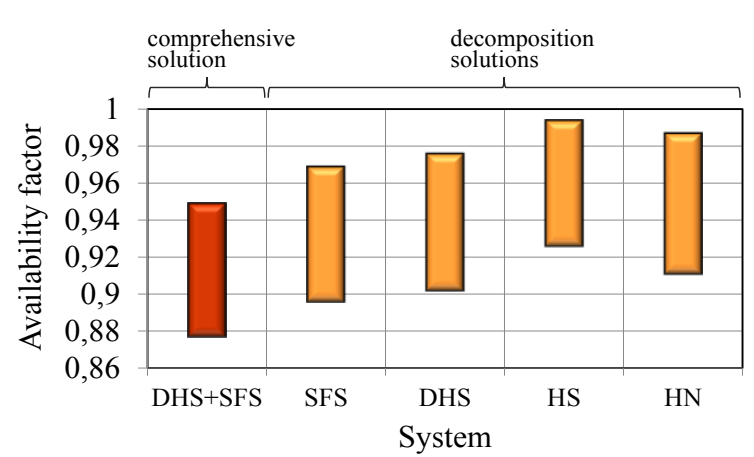

Fig. 13. Ranges of nodal AF for comprehensive and decomposition analysis of the reliability of DHS

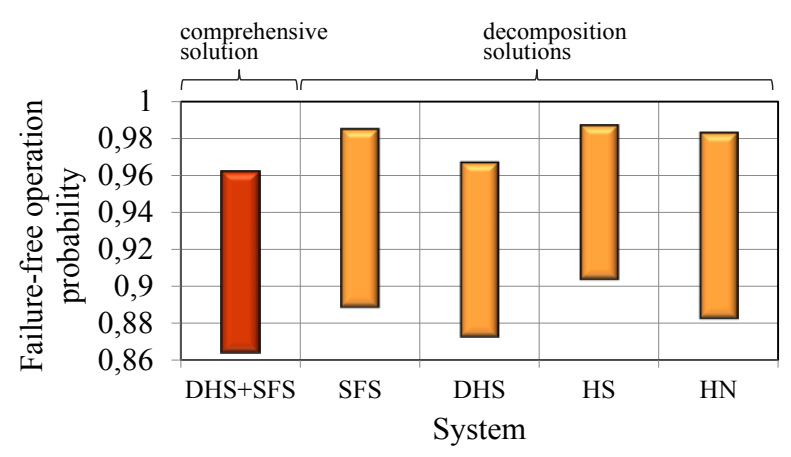

Fig. 14. Ranges of nodal FOP for comprehensive and decomposition analysis of the reliability of DHS

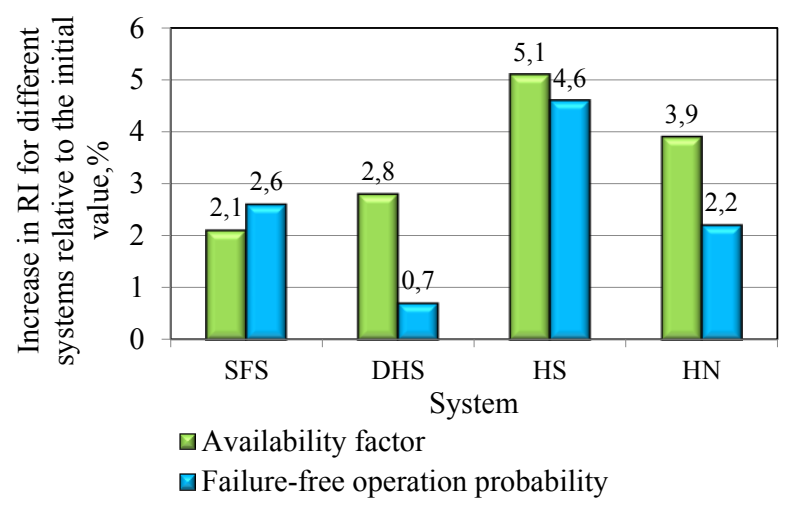

Fig. 15. Changes in nodal RI (AF and FOP) for SFS, DHS and subsystems of DHS in relation to the comprehensive level of this indices (the ratio of indices of decomposition and comprehensive reliability assessment)

capacity of HS (CHP-5) is significantly higher than the required generation for heat supply to house-hold consumers of the city, since most of this power covers technological loads. Therefore, there is an additional reserve for heating during periods of low heat loads.

3. The reliability of the reduced level of heat supply to consumers, characterized by index FOP, is affected to a greater extent by the failures of the DHS components (Fig. 14 and Fig. 15). Decomposition of RI is showed that $\mathrm{HN}$ is a less reliable subsystem. In this regard, one of the main directions of increasing the reliability of DHS are related to the implementation of a set of measures for the component and structural redundancy of HN. Such, the additional looped network connections 
(bypass) in the network and duplication of some sections will provide the required level of reduced heating to consumers in emergency modes. Replacing the network components with more reliable ones and increasing its restoration rates (incl. due to improvement of emergency and restoration service) will increase the values of both indices (AF and FOP).

4. The presented results of the reliability analysis are aimed at obtaining the basis for making further decisions on searching the optimal ratio of measures to increase the reliability of heat supply to consumers. The rational distribution of reliability both in DHS (i.e. for subsystems - HS and HN) and SFS, and in the ways to ensure it (functional, component, structural redundancy, fuel reserves, energy storages, etc.) are a subject of special research of the problems of reliability synthesis. For example, the methodology for the optimal increase/ensuring the reliability parameters of DHS components as the one of the problem of reliability synthesis is considered in articles [14] and [15]. Some reliability optimization issues for the DHS with prosumers are presented in works [17-19].

\section{Conclusion}

As a result of the provided researches, scientific and methodological ensuring was developed for the comprehensive solution of a number of key technical, economic and organizational tasks of designing, functioning and developing modern DHS, taking into account their relationship. Within the framework of the developed scientific and methodological support, the following basic problems were solved: optimization of levels of district heating in DHS with feasibility study for connecting new consumers, selection of optimal forms and models of heating market for DHS, comprehensive analysis and ensuring (optimization) reliability of DHS taking into account the fuel supply of HS, and also other additional problems.

The developed scientific and methodological platform makes it possible to solve different problems for the innovative transformation of DHS (designing, management, reliability and others) in a joint complex, taking into account their logical relationship and methodological compatibility, which ultimately provides support for decisions to achieve the maximum efficiency, economy and reliability of heat supply to consumers.

Provided practical studies have confirmed the applicability and efficiency of the methods and models developed in the project, not only for test calculation schemes but also for existing DHS of cities. As results the new characteristics for studied systems were obtained, directions for their effective functioning and development were formulated with the joint solution of the complex of the most key and relevant technical and economic problems for modern DHS. The implementation of provided methodology into the practice of designing and development of DHS will contribute the increasing their efficiency and reliability, and transition the heat supply industry into an effective part of the economy.

\section{Acknowledgements}

The research was performed at Melentiev Energy Systems Institute SB RAS within the framework of scientific project III.17.4.1 No. AAAA-A17-117030310432-9 with partial financial support of Russian Foundation for Basic Research (Grant №20-08-00488A)

\section{References}

1. V. Stennikov, E. Iakimetc. Energy 110, 157-65 (2016)

2. V. Stennikov, E. Mednikova, I. Postnikov, A. Penkovskii, T. Dobrovolskaya. Industrial power engineering 11, 25-32 (2017)

3. E. Mednikova, V. Stennikov, I. Postnikov. Industrial power engineering 2, 13-20 (2018)

4. V. Stennikov, E. Mednikova, I. Postnikov, A. Penkovskii. Environmental and Climate Technologies 23(2), 207-21 (2019)

5. V. Stennikov, E. Mednikova, I. Postnikov. MATEC Web of Conferences "2018 International Scientific Conference "Investment, Construction, Real Estate: New Technologies and Special-Purpose Development Priorities (ICRE 2018)" 212, 8 (2018)

6. A. Penkovskii, V. Stennikov, O. Khamisov. Thermal Engineering 62, 598-606 (2015)

7. A. Penkovskii, V. Stennikov. Thermal Engineering 65(7), 443-52 (2018)

8. A. Penkovskii, V. Stennikov, E. Mednikova, I. Postnikov. Energy 161, 193-201 (2018)

9. A. Penkovskii, V. Stennikov. Energy Reports 6(2), 187-93 (2020)

10. A. Penkovskii, V. Stennikov, I. Postnikov. Energy Procedia 158, 3439-44 (2019)

11. A. Penkovskii, V. Stennikov, O. Khamisov, E. Mednikova, I. Postnikov. Energy Procedia 105, 3158-63 (2017)

12. V. Stennikov, I. Postnikov. Power Technology and Engineering 47(6), 446-53 (2014)

13. V. Stennikov, I. Postnikov. Bulletin of Russian Academy of Science. Energy 2, 107-21 (2011)

14. I. Postnikov, V. Stennikov, E. Mednikova, A. Penkovskii. Energy Procedia 105, 3083-8 (2017)

15. I. Postnikov, V. Stennikov, E. Mednikova, A. Penkovskii. Applied Energy 227, 365-74 (2018)

16. I. Postnikov, V. Stennikov. Energy Reports 6(2), 293-8 (2020)

17. I. Postnikov, V. Stennikov, A. Penkovskii. Energy Procedia 158, 2530-5 (2019)

18. I. Postnikov. Energy Reports 6(2), 214-20 (2020)

19. I. Postnikov. IEEE Xplore "International MultiConference on Industrial Engineering and Modern Technologies (FarEastCon)", 1-7 (2019) 